\title{
Out-of-pocket cost of drug abuse consequences: results from Iranian National Mental Health Survey
}

Masoumeh Amin-Esmaeili ${ }^{1}$, Mitra Hefazi ${ }^{2}$, Reza Radgoodarzi ${ }^{1}$, Abbas Motevalian ${ }^{3}$, Vandad Sharifi ${ }^{4}$, Ahmad Hajebi $^{5}$ and Afarin Rahimi-Movaghar ${ }^{1}$

$$
\begin{aligned}
& \text { التكلفة الشخصية للعواقب الناجمة عن تعاطي المخدر ات: نتائج مسح الصحة النفسية الوطني الإيراني }
\end{aligned}
$$

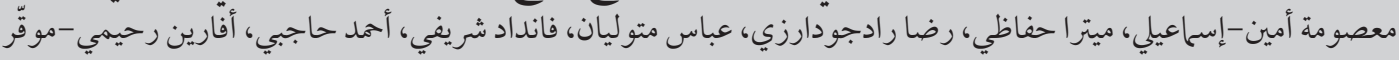

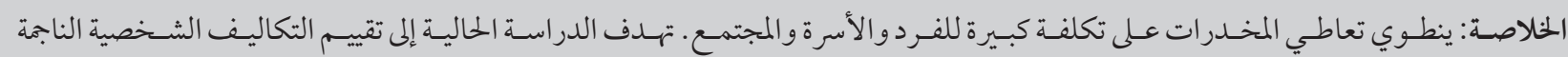

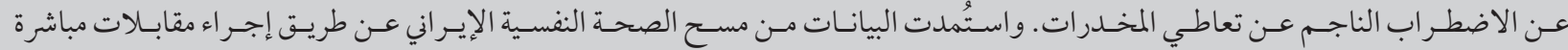

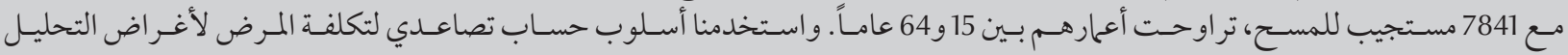

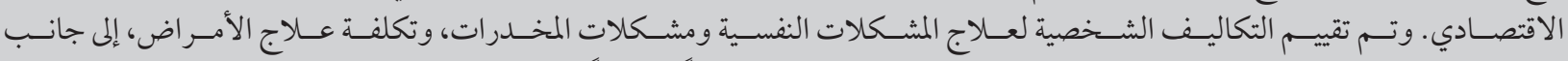

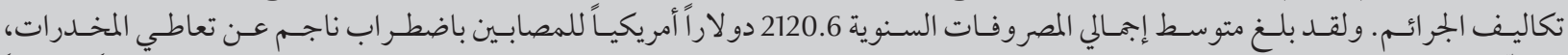

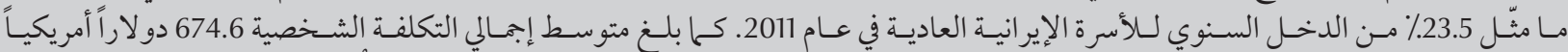

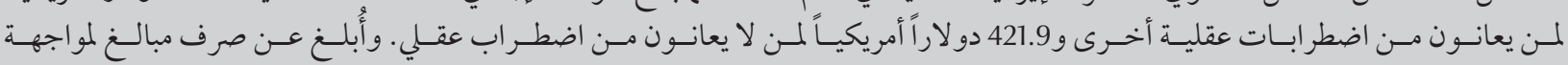

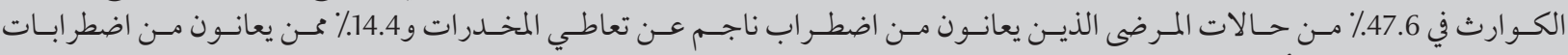

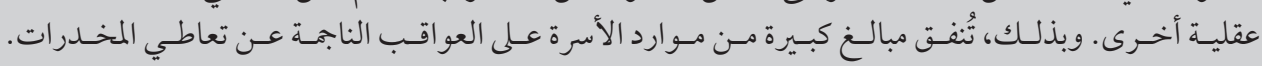

ABSTRACT Drug abuse has significant cost to the individual, the family and the society. This study aimed to assess out of-pocket costs of consequences of drug use disorder. Data were drawn from the Iranian Mental Health Survey (IranMHS) through face-to-face interviews with 7841 respondents aged 15-64 years. We used a bottom-up cost-ofillness method for economic analysis. Out-of-pocket costs for treatment of mental and drug problems, treatment of medical illnesses, as well as costs of crimes were assessed. The average of total annual expense was US\$2120.6 for those with drug use disorder, which was $23.5 \%$ of annual income of an average Iranian family in the year 2011 . The average of total out-of-pocket cost was US\$ 674.6 for those with other mental disorder and US\$ 421.9 for those with no mental disorder. Catastrophic payment was reported in $47.6 \%$ of the patients with drug use disorder and $14.4 \%$ of those with other mental disorder. Thus, considerable amount of family resources are spent on the consequences of drug use.

Coût des paiements directs engendrés par l'abus de substances psychoactives : résultats de l'enquête nationale iranienne sur la santé mentale

RÉSUMÉ L'abus de substances psychoactives entraîne un coût important pour les individus, les familles et la société. La présente étude avait pour objectif d'évaluer le coût des paiements directs engendrés par les troubles liés à l'utilisation de substances psychoactives. Les données ont été extraites de l'enquête nationale iranienne sur la santé mentale au moyen d'entretiens en face à face avec 7841 participants âgés de 15 à 64 ans. Nous avons utilisé une méthode du coût de la maladie de type ascendant pour l'analyse économique. Les coûts des paiements directs pour le traitement des troubles mentaux ou des problèmes de drogue, le traitement des maladies, ainsi que les coûts engendrés par les crimes ont été évalués. La moyenne des dépenses annuelles totales était de 2120,6 dollars US pour les personnes atteintes de troubles liés à l'utilisation de substances psychoactives, soit 23,5\% du revenu annuel d'une famille iranienne moyenne pour l'année 2011. Le coût total moyen des paiements directs était de 674,6 dollars US pour ceux souffrant de troubles mentaux, et de 421,9 dollars US pour ceux exempts de troubles mentaux. Des dépenses catastrophiques ont été rapportées pour 47,6 \% des patients souffrant de troubles liés à I'utilisation de substances psychoactives, et pour 14,4 \% de ceux souffrant d'autres types de troubles mentaux. Une part considérable des ressources des familles est donc dépensée du fait de l'utilisation de substances psychoactives.

IIranian National Centerfor Addiction Studies, Tehran University of Medical Sciences, Tehran (Correspondence to: A. Rahimi-Movaghar: rahimia@ sina.tums.ac.ir). ${ }^{2}$ Iranian Research Center for HIV/AIDS, Tehran University of Medical Sciences, Tehran. ${ }^{3}$ School of Public Health, Iran University of Medical Sciences, Tehran. ${ }^{4}$ School of Medicine, Tehran University of Medical Sciences, Tehran. ${ }^{5}$ Mental Health Research Center, Iran University of Medical Sciences, Tehran, Islamic Republic of Iran.

Received: 31/05/16; accepted : 12/02/17 


\section{Introduction}

In the Islamic Republic of Iran, prevalence of drug use disorder (DUD) is higher than the global average. It is mainly because of opioids being the most common drug of use in the Islamic Republic of Iran (1) in comparison to most other countries where cannabis is the most commonly used drug (2). In the past 15 years, drug use, mainly injecting drug use has contributed significantly to infectious diseases like HIV infection and viral hepatitis (3-5). Drug abuse is also associated with other psychiatric comorbidity, criminal behaviour and violence (1). There is evidence that the burden of DUD has increased during recent decades in the Islamic Republic of Iran (6).

Drug abuse imposes significant costs on the individual, families and society. These include costs of illness, injury, crime, loss of productivity and early death. Costs of drug abuse consequences can be classified into several categories (7-9): 1) direct costs that include costs of treatment (i.e., drug costs, costs of treatment of other mental health comorbidity, and costs of other medical diseases and social costs (i.e., crime-related costs, and costs for compensating impairment in usual roles and functions); and 2) indirect cost of premature mortality and work absenteeism. There might be other costs, such as intangible costs, which are not included in these categories. These costs might be covered by those with DUD and their families, government, insurance companies, charities and other sectors.

In this paper we present the first national estimates of out-of pocket costs of drug abuse consequences for all the above categories, using the data from Iranian National Mental Health Survey (IranMHS). IranMHS was a household survey that included a national representative sample of those with DUD, those with other mental disorder (MD) and those with no MD. Out-of pocket costs of several main consequences of DUD over the past 12 months were assessed in the survey using a bottom-up cost-of-illness study method. The results were compared in the three groups.

\section{Methods}

IranMHS was a cross-sectional household survey with a representative sample of the Iranian population aged 15-64 years. It was conducted to assess the 12-month prevalence and severity of psychiatric disorders in the Iranian adult population and to determine the pattern of healthcare utilization and cost of services.

\section{Sample}

The participants were selected from a 3-stage clustered sample of noninstitutionalized household residents. Those who were unable to understand Farsi (the official and widely used language in the Islamic Republic of Iran) or people with severe medical or psychiatric illness, which made them unable to respond to the questions, and those with non-Iranian nationalities, were excluded.

\section{Field procedures}

The data collection was carried out by a cohort of 232 trained interviewers. Interviewers had a minimum of BA in psychology and some clinical experience and were familiar with the culture and language of the geographical area. They underwent intensive training specifically on administration of Composite International Diagnosis Interview (CIDI) using a standard protocol developed by the World Health Organization, and on the other subjects including general interview techniques, proper administration of the other questionnaires, ethical considerations, sampling and field work. The field work was carried out between January and June 2011 through a face-to-face interview and a total of 7886 individuals completed the interview. Almost all data were collected through a face-to-face interview with the selected participants except data on cost of the services, which was provided by the most informed member of the household. Strict quality control procedures were applied at all stages of the field work and data entry, as described previously (10).

\section{Measures}

\section{Mental disorders}

To assess psychiatric disorders including drug and alcohol use disorders, we applied CIDI version 2.1. It is a fully structured diagnostic interview based on the Diagnostic and Statistical Manual of Mental Disorders (DSMIV) and International Classification of Diseases - 10th Revision (ICD-10). The Persian version of the paper and pencil interview form (PAPI) of CIDI 2.1 had been validated and had shown adequate psychometric properties in a clinical setting (11) and in the Iranian general population $(10,12)$.

Twelve-month substance use disorders including abuse or dependence to alcohol, cannabis, opioids, amphetamine-type stimulants, hallucinogens, inhalants and other drugs such as cocaine were examined by CIDI 2.1. Other psychiatric disorders consisted of mood disorders including major depressive disorder, dysthymia, bipolar I disorder; anxiety disorders including panic disorder (with and without agoraphobia), agoraphobia without panic, obsessivecompulsive disorder, social phobia, and post-traumatic stress disorder were also assessed by the same instrument. Due to inadequate psychometric properties of CIDI 2.1 for assessing psychotic disorders, a 2-stage procedure was used for detection of any psychotic disorders: screening using the $G$ section of the CIDI 2.1 and then interview by a psychiatrist using the Structured Clinical Interview for DSM-IV Axis I Disorders (SCID-I). The Persian translation of SCID had shown acceptable to good reliability and validity indices $(13,14)$. 
Details of the procedure applied for assessing psychotic disorders and dealing with non-response and missing data were published elsewhere $(10,15)$.

\section{Service utilization}

We developed a questionnaire for assessing service utilization, mainly based on 2 other instruments: Services section of the World Mental Health Survey, and the questionnaire used in the Health Services Utilization Study of Iran. Next, it was modified culturally and tailored according to the existing mental healthcare services in the Islamic Republic of Iran. It consisted of an inventory, which included the following items.

(1) Service use due to mental and drug problems in the past 12 months:

- Health care: inpatient (hospitalization and short-term stay for residential treatment) and outpatient services, pharmacies, and harm reduction services from drop-in centres; by type of health care setting, including drug treatment facility and by provider;

- Non-health care: self-help groups and traditional services.

(2) Healthcare service use due to medical problems:

- inpatient services in past 12 months

- outpatient services in past 2 weeks

Face and content validity and inter-rater reliability of the service use questionnaire were evaluated in the preliminary phase of the IranMHS and described elsewhere (10).

\section{Out-of-pocket costs and economic analysis}

We used a bottom-up cost-of-illness method for economic analysis. In this method, cost data are collected by people with a certain disease, assessing their individual cost by interview or review of their medical records. Next, the mean cost per person is multiplied by the number of persons to estimate the total cost (16). For assessing out-of-pocket cost of services, a series of questions according to the type of service was added to the end part of the questionnaire on service utilization. The costs assessed in this study included costs for treatment, social costs and indirect costs.

(1) Out-of-pocket costs for treatment.

- Health costs of inpatient care: the payments for all events of inpatient treatment for mental and drug use problems and the last hospitalization for medical reasons were measured, if it was in the past 12 months. Then, in order to calculate the 12-month costs of all hospitalizations for medical reasons, the payment for each hospitalization was multiplied by the number of hospitalizations of each individual in the last 12 months. The payments for inpatient care included the bills for the centres, as well as any separate bill paid for the physicians, medications or medical supplies during the hospitalization period.

- Health costs of outpatient care: a list of items was provided to those who had used the service and the respondents were asked to report the exact payment for the item. The items included payment for a therapist's visit, medication, counselling and psychotherapy, psychometric tests, and the costs of any referrals by the therapist for laboratory tests; electroencephalography; evoked potential, body and brain scans; radiology; sonography; electrocardiography and other cardiac diagnostic tests; gastrointestinal examinations; outpatient electroconvulsive therapy; and other costs. Healthcare cost for mental and medical problems were gathered by questioning the payments for using the services in the past 3 months, and past 2 weeks, respectively; then the payments were multiplied by 4 or 26 to calculate the 12-month costs, respectively.

- Other health costs: this included costs of medication when the individual attended a pharmacy, or any cost for receiving harm reduction services from drop-in centres.
- Non-health costs of using any of the above health services: the costs included costs of transportation, as well as accommodation of the family, if the location of service was out of the city/ village of the individual.

- Non-health care costs: it included costs of self-help groups and traditional services, as well as transportation and accommodation.

(2) Out-of-pocket social costs: social costs in the past 12 months included payment of fines set by courts, and costs related to the police and prisons.

(3) Indirect costs have been defined as the value of the days of work lost due to absenteeism in the past 12 months. They were assessed by asking the individuals about the number of days out of work due to mental problems and their average wage for 1 day.

Data on costs were collected and calculated in Iranian rial and are presented in the text and tables in US\$ (2011). All currency conversions were conducted post-analysis based on the average official exchange rates for 2010, which was 10290 Iranian rial for each US\$1.00 (17).

Catastrophic payment: with a series of questions we assessed the financial burden of the mental disorder imposed on the respondent or the family. This indicator was assessed for 2 situations: 1) psychiatric hospitalization in the past 12 months; and 2) general financial burden of the mental disorder in the past 12 months. When the person/family spent their savings, sold their assets or borrowed money for treatment/compensation of the disease it was defined as catastrophic payment.

\section{Statistical analysis}

Survey weights were used in all analyses. The consolidated weights were the joint product of inverse probability of unit selection into the sample (w1), non-response weights (w2) and poststratification weights (w3).w1 included weighting by the number of eligible individuals in each household and w3 
was calculated by dividing the proportion of individuals in each stratum in the 2006 National Census by the proportion of the same group in the sample. Based on 5-year age groups, sex and urbanicity status in each of 31 country provinces, 1240 post-stratification weights were generated. All the results are based on complex sample survey analysis, in which, provinces are considered as strata and blocks as clusters. Principle component analysis of household asset data was applied to create a socioeconomic status indicator for each household, which was categorized into 3 levels with approximately equal numbers of individuals: low, middle and high. Analyses were conducted using STATA version 12 (STATA Corporation, College Station, TX, USA). All findings presented in this paper, including percentages and costs are weighted and are provided for the DUD, other $\mathrm{MD}$ and no MD groups.

\section{Ethical considerations}

The research protocol was approved by the Ethics Committee of Tehran University of Medical Sciences in Iran (No. IR.TUMS.REC.1394.1900). Informed consent was obtained from all participants. They could refuse to respond to any question. The interviews had to be held in privacy. Data processing and analysis were done anonymously.

\section{Results}

A total of 9150 individuals were approached by interviewers and 7886
(86.2\%) agreed to participate. These included 3387 (42.9\%) men and 4499 (57.1\%) women. Characteristics of the study sample have been described elsewhere (15). A total of 7841 individuals $(85.7 \%)$ completed the drug section of CIDI, of whom, $2.1 \%$ met the DSM-IV criteria for 12-month DUD and $21.4 \%$ met the criteria for other MD. Those with DUD were more likely to be unemployed and be from lower socioeconomic groups and less likely to have a supplementary health insurance than those with other or no MD (Table 1).

\section{Service utilization}

One hundred (67.3\%) of those with DUD and 914 (50.4\%) of those with other MD had used any kind of health or non-health services for mental or drug problems in the past 12 months. Receiving inpatient care and attending self-help groups were higher in those with DUD than those with other MD ( $14.9 \%$ vs $1.2 \%$ and $30.1 \%$ vs $1 \%$ ), respectively. Using pharmacies and traditional services was also more common in those with DUD ( $40.7 \%$ vs $23.5 \%$ and $40.5 \%$ vs $24.7 \%$ ), respectively. However, utilizing outpatient service for mental/ drug problems was almost equal in the two groups (29\% and 29.4\%) (Table 2).

Hospitalization for medical reasons in the past 12 months was higher in those with DUD (14.3\%) and other MD (10.2\%) than in those with no MD (7\%). Outpatient service use for medical reasons was higher in those with DUD (28.4\%) and other MD (28.9\%) than those with no MD (20\%) (Table 2).

\section{Out-of-pocket cost for treatment}

Costs for mental health care in the past 12 months, including health and nonhealth costs, were assessed separately, and both for those who had used the specific service and the average for those who have used any services (Table 3). Mean total cost for mental health care for the 100 patients who had used any services and were diagnosed with DUD was US\$ 439.6, while it was US\$ 144.7 for 914 with other MD. Health and non-health costs of inpatient, outpatient and traditional service use for mental/ drug problems were higher in those with DUD than in the other 2 groups. Catastrophic payment in the past 12 months for hospitalization for mental and drug problems was reported by $26.4 \%$ of those with DUD and by $25.6 \%$ of those with other MD. Out-ofpocket costs of medical care in the past 12 months were significantly higher in those with DUD (US\$ 427.4) than those with other MD (US\$267.2) and no MD (US\$238.7), which was mainly due to the higher payments for inpatient care (Table 4).

\section{Social costs}

Illegal acts resulting in fines and incarceration were more common in those with DUD (8.5\%) than those with other MD (1.1\%) and no MD (0.5\%) (Table 5). Payments for those convicted for illegal acts were also higher in patients with DUD. The average last 12-month

\begin{tabular}{|c|c|c|c|}
\hline & DUD & Other MD & No MD \\
\hline & Weighted \% & Weighted \% & Weighted \% \\
\hline Unemployed $^{\text {a }}$ & $24.9(17.0-32.8)$ & $12.1(10.3-14.1)$ & $8.3(7.5-9.2)$ \\
\hline Low socioeconomic status & $43.0(33.7-52.4)$ & $25.4(22.8-28.0)$ & $20.8(19.4-22.3)$ \\
\hline Having health insurance & $69.5(60.7-78.2)$ & $76.4(73.8-78.9)$ & $81.5(80.1-82.8)$ \\
\hline $\begin{array}{l}\text { Having supplementary health } \\
\text { insurance }\end{array}$ & $5.2(0.7-9.7)$ & $16.7(14.4-19.0)$ & $17.6(16.2-19.0)$ \\
\hline
\end{tabular}

${ }^{a}$ Those who had not worked in the past week and could not be categorized as housewife, student, soldier and retired were categorized as unemployed. DUD = drug use disorder; $M D=$ mental disorder. 


\begin{tabular}{|c|c|c|c|c|c|c|}
\hline \multirow[t]{2}{*}{ Types of services } & \multicolumn{2}{|r|}{$\begin{array}{l}\text { DUD } \\
(n=151)\end{array}$} & \multicolumn{2}{|r|}{$\begin{array}{l}\text { Other MD } \\
(n=1729)\end{array}$} & \multicolumn{2}{|r|}{$\begin{array}{l}\text { No MD } \\
(n=5961)\end{array}$} \\
\hline & $\mathbf{N}$ & Weighted \% & $\mathbf{N}$ & Weighted \% & $\mathbf{N}$ & Weighted \% \\
\hline \multicolumn{7}{|l|}{$\begin{array}{l}\text { Health care for mental/drug } \\
\text { problems }\end{array}$} \\
\hline Inpatient care & 23 & $14.9(8.1-21.6)$ & 22 & $1.2(0.7-1.8)$ & 11 & $0.2(0.05-0.3)$ \\
\hline Outpatient care & 42 & $29.0(20.1-37.8)$ & 560 & $29.4(26.7-32.1)$ & 534 & $8.3(7.4-9.1)$ \\
\hline Pharmacy & 57 & $40.7(31.2-50.2)$ & 416 & $23.5(21.2-25.9)$ & 345 & $5.8(5.0-6.5)$ \\
\hline Drop-in centres & 1 & $0.6(0-1.8)$ & 0 & 0 & 1 & $0.03(0-0.08)$ \\
\hline \multicolumn{7}{|l|}{$\begin{array}{l}\text { Non-health care for mental/ } \\
\text { drug problems }\end{array}$} \\
\hline Services for self-help group & 41 & $30.1(21.0-39.2)$ & 18 & $1.0(0.5-1.6)$ & 29 & $0.5(0.3-0.7)$ \\
\hline Traditional services & 61 & $40.5(31.3-49.8)$ & 458 & $24.7(22.1-27.2)$ & 379 & $6.2(5.5-7.0)$ \\
\hline \multicolumn{7}{|l|}{ Health care for medical illness } \\
\hline Medical hospitalization & 23 & $14.3(7.5-21.0)$ & 188 & $10.2(8.5-11.8)$ & 432 & $7.0(6.2-7.8)$ \\
\hline $\begin{array}{l}\text { Outpatient service for } \\
\text { medical illness }^{\text {a }}\end{array}$ & 39 & $28.4(19.5-37.3)$ & 498 & $28.9(26.4-31.5)$ & 1209 & $20.0(18.7-21.3)$ \\
\hline
\end{tabular}

${ }^{a}$ Outpatient service for medical illness was determined only for the past 2 weeks. $D U D=$ drug use disorder; $M D=$ mental disorder.

social costs for a patient with DUD was US\$655.6, which was higher than for the other groups (US29.1 for other MD and US\$9.7 for no MD).

\section{Indirect costs}

Number of days out of work due to mental/drug problems during the past 12 months was ascertained from those who were employed. The mean (95\% confidence interval) was 44.3 (29.2-59.5), $18.3(13.0-23.6)$ and 5.8 (3.9-7.6) days in those with DUD, other MD and no MD, respectively. Daily income was also reported by the three employed groups to be US\$17.6, US\$ 16.5 and US\$ 19.6, respectively. Therefore, the weighted average of indirect cost due to the work absenteeism in the past 12 months is calculated as 598 (364.1-831.9) in those with DUD, $233.6(146.8-320.5)$ in those with other MD and 93.6 (51.0-136.2) in those with no MD.

\section{Total costs}

The total last 12-month costs of the 3 groups for 2011 are shown in Figure 1. The expenses were US\$2120.6 for individuals with DUD and US\$ 674.6 for those with other MD. For those with DUD, receiving care for mental/ the total expenses, respectively. These drug problems and medical problems costs were $21.4 \%$ and $39.6 \%$ of the total accounted for $20.7 \%$ and $20.2 \%$ of costs in those with other MD. For the

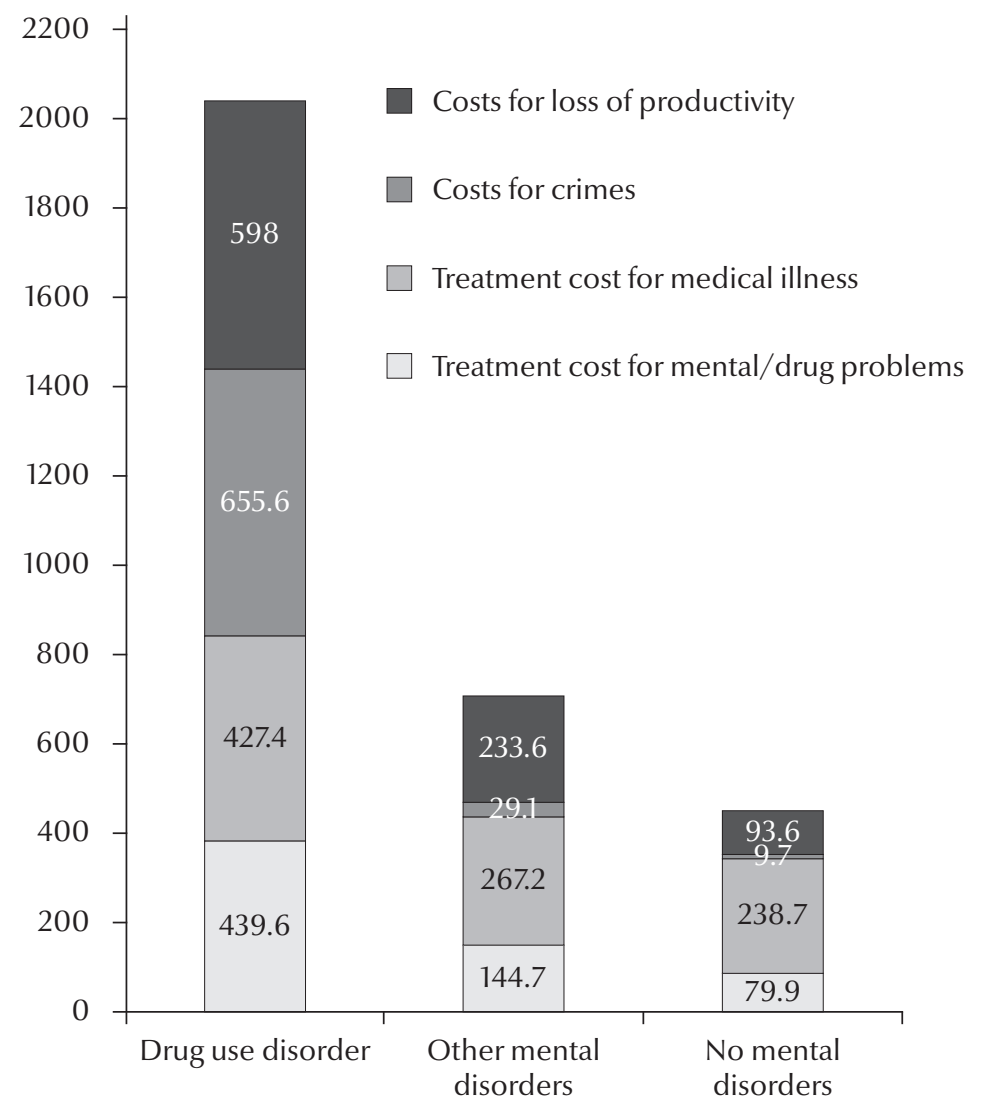

Figure 1 Total out-of-pocket costs (US\$) in individuals with DUD, other MD and no $M D$ in 2011. DUD = drug use disorder; $M D=$ mental disorder. 


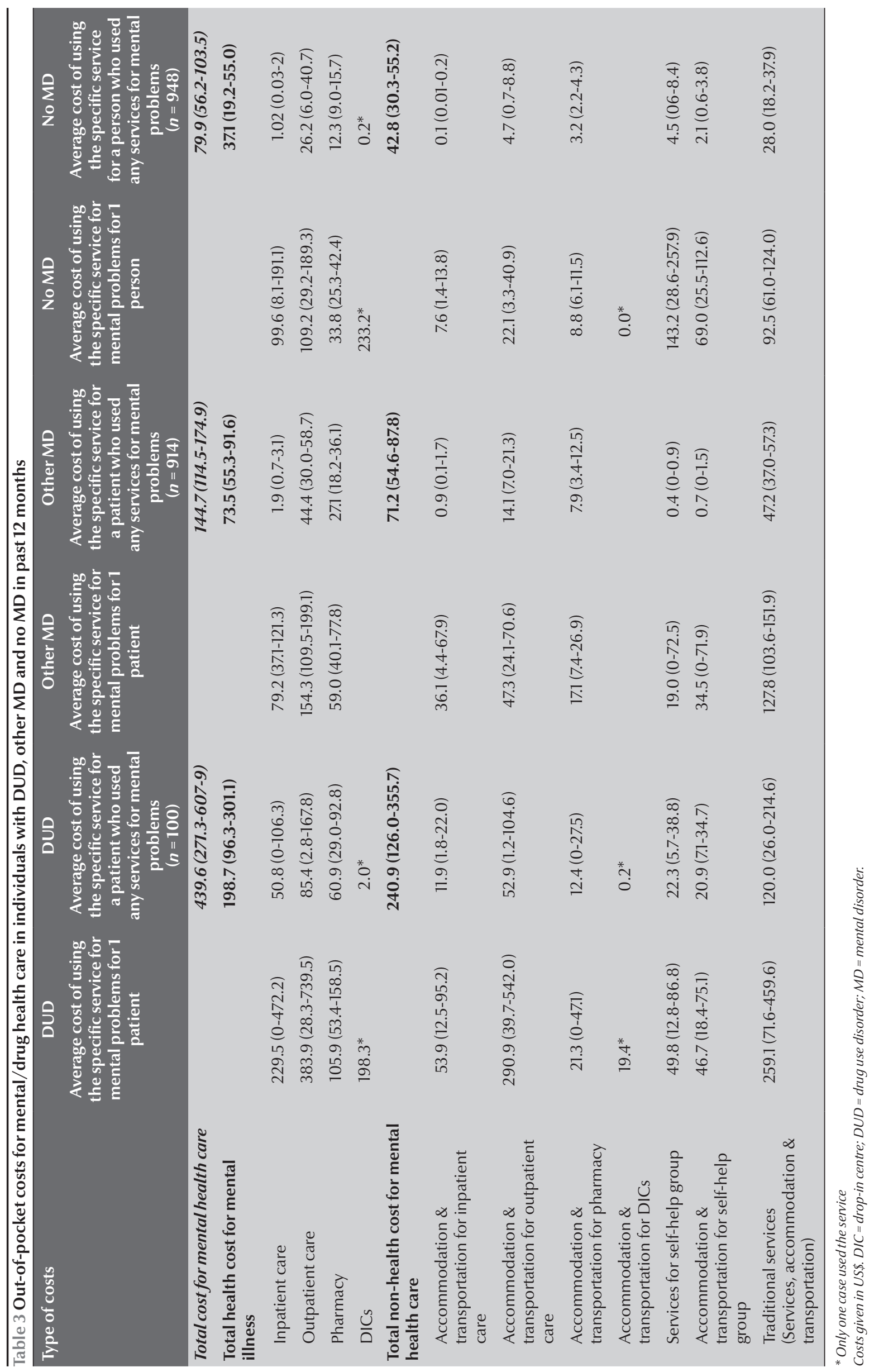




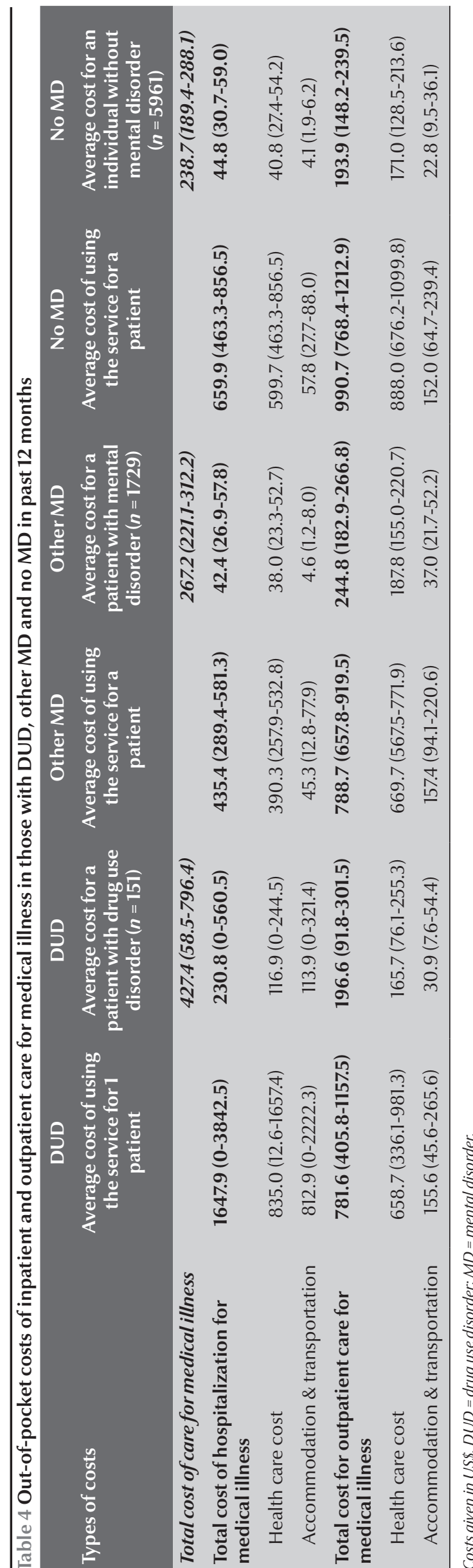

individuals with DUD, $30.9 \%$ of the costs were due to crimes, whereas crime constituted $4.3 \%$ of the total costs of those with other MD. Work absenteeism was responsible for $28.2 \%$ of the costs of DUD and $34.6 \%$ of the costs of other MD. The ability of the individual or the family to pay the overall costs of the mental and drug problems in the past 12 months was determined. Catastrophic payment was reported in $47.6 \%$ of the patients with DUD and $14.4 \%$ of those with other MD.

\section{Discussion}

This study revealed that, in 2011, individuals with DUD spent an average of US $\$ 2120$ for receiving care, compensating illegal acts and for work absenteeism. According to an official report [adapted from the Statistical Center of Iran (18)], the average earning of a family in 2011 was US\$ 9033, therefore, $23.5 \%$ of annual family income is spent on the consequences of drug use. This is 3.1 times higher than similar expenses of a patient with other MD. When the respondents were asked about the overall payment of the family in the past 12 months for mental and drug problems, catastrophic payment was reported in almost half of the patients with DUD, which was 3 times higher than for those with other MD. This is in line with the findings from another Iranian national household survey that assessed the general income and health expenditure of households, and showed that expenditure for drug addiction treatment had the greatest impact on household exposure to catastrophic health expenditure (19).

Many cost assessments of drug abuse treatment have been conducted from the treatment-provider perspective, and less is known about the client-specific costs of attending treatment (20), which we used in this study in a representative sample of the general population. We found that, on average, $20.7 \%$ of the out-of-pocket expenses of those with DUD is spent on treatment and care for their mental/drug problem. The service with the highest past 12-month cost was outpatient treatment, followed by traditional services and inpatient care. Attending self-help groups was common, but was associated with the least cost.

Although the rate of outpatient use of health services for mental/drug problems was similar for those with DUD and other MD, the costs of using these services was higher in the patients with DUD. In the Islamic Republic of Iran, the majority of opioid addiction treatment is delivered in methadone maintenance programmes. Most of the facilities are privately managed and patients pay for their treatment expenses. These services also need frequent visits to the clinics and result in higher health costs, as well as non-health costs of transportation.

Drug abusers were hospitalized or stayed in short-term residential treatment settings more frequently than those 


\begin{tabular}{|c|c|c|c|c|c|c|}
\hline \multirow[t]{2}{*}{ Social problems } & \multicolumn{2}{|c|}{$\begin{array}{c}\text { DUD } \\
(n=151)\end{array}$} & \multicolumn{2}{|c|}{$\begin{array}{l}\text { Other MD } \\
(n=1729)\end{array}$} & \multicolumn{2}{|c|}{$\begin{array}{c}\text { No MD } \\
(n=5961)\end{array}$} \\
\hline & $n$ & Weighted \% & $n$ & Weighted \% & $n$ & Weighted \% \\
\hline Fined by court & 12 & $8.5(3.3-13.7)$ & 18 & $1.1(0.5-1.6)$ & 28 & $0.5(0.3-0.8)$ \\
\hline $\begin{array}{l}\text { Arrested or } \\
\text { imprisoned }\end{array}$ & 13 & $9.5(3.7-15.3)$ & 22 & $1.5(0.8-2.2)$ & 30 & $0.5(0.3-0.7)$ \\
\hline
\end{tabular}

$D U D=$ drug use disorder $M D=$ mental disorder .

with other MD. The out-of-pocket cost of the inpatient treatment care was also higher for each event of hospitalization. More than $25 \%$ of patients reported catastrophic payment for receiving inpatient care in the past 12 months. Longer duration of stay and more frequent hospitalization might have been the reasons for higher costs. Similar findings have been reported in other studies. Olsson et al. reported a high frequency and high cost of inpatient treatment (detoxification and shortterm rehabilitation) among women with substance dependence in Sweden (21).

One of the main reasons behind higher out-of-pocket costs of health services for drug users is the lack of coverage of insurance for DUD. In 2011, there was no such coverage for people with any type of insurance, as well as supplementary insurance in the Islamic Republic of Iran. Insurers refused to reimburse outpatient and inpatient services when the patient was diagnosed with substance use disorder. In recent years, there have been efforts to improve the coverage and reimburse the first 6 months of methadone maintenance treatment in public drug treatment clinics; however, this regulation is still not operational. In the meantime, about one third of those with DUD are not insured and they or their family pay all health expenses. Insurance coverage for DUD is a global issue and the improvements have been slow. Even in countries with such improvements, its impact on receiving adequate levels of treatment might not happen in the short term (22).
Self-help groups are the most common services used for drug treatment in the Islamic Republic of Iran (1). The cost of using these services is lower than other services and they do not impose any burden on the government. Using these services is also associated with long-term benefits, such as reduced substance use, improved psychosocial functioning and reduced healthcare costs (23). Such benefits have also been reported from inside the Islamic Republic of Iran (24). Promoting selfhelp group involvement can improve outcomes while reducing the costs of long-term care (25).

Use of traditional services for men$\mathrm{tal} /$ drug problems is also prevalent and is associated with considerable cost. It has long been considered that herb selling and its illegal involvement in treatment of drug abuse and mental problems are a public health issue (26) and need attention from health regulatory bodies. Public education in this domain is also of importance and can decrease the burden of costs imposed by using services with no evidence, which might cause more harm than benefit.

We found that hospitalization for medical purposes was more common and was associated with a higher cost in those with DUD than those with no MD. However, receiving outpatient care and its costs were almost similar in those with DUD, other MD and no MD. Overall, the costs of care for medical purposes overcome the costs of drug/mental problems. This finding might be due to the higher costs of diagnostic tests, medications and procedures needed for the management of medical illnesses.

It was also reported from the United States of America (USA) that the costs of medical care were $\sim 2$-fold higher than the costs of drug-related services (7). The utilization of healthcare services, including outpatient, emergency department and inpatient services and the associated costs were higher in patients with than those without substance use (27). There is evidence that patients with untreated substance use disorders have higher service utilization for medical and emergency problems. Rockett et al. reported that patients with unmet substance treatment need had $46 \%$ excess utilization of emergency department services and generated US\$ 1568 per patient, in annual extra emergency and hospitalization charges (27).

In our study, the highest costs for individuals and their families were for compensation for crime, followed by work absenteeism. Similar findings have been reported from the USA and France $(7,28-30)$. A person with DUD is more likely to be involved in criminal activities. This includes both drug-defined criminal activities (e.g., distribution, sales and possession of drugs) and drug-related criminal activities (e.g., participation in illegal activity to obtain money to purchase drugs, or criminal acts performed under the influence of drugs) (31). Our study showed that drug abusers were 8 times more likely to be fined by court and 6 times more likely to be arrested or imprisoned than a person with other MD.

One of the main aspects of cost of drug abuse consequences is the indirect 


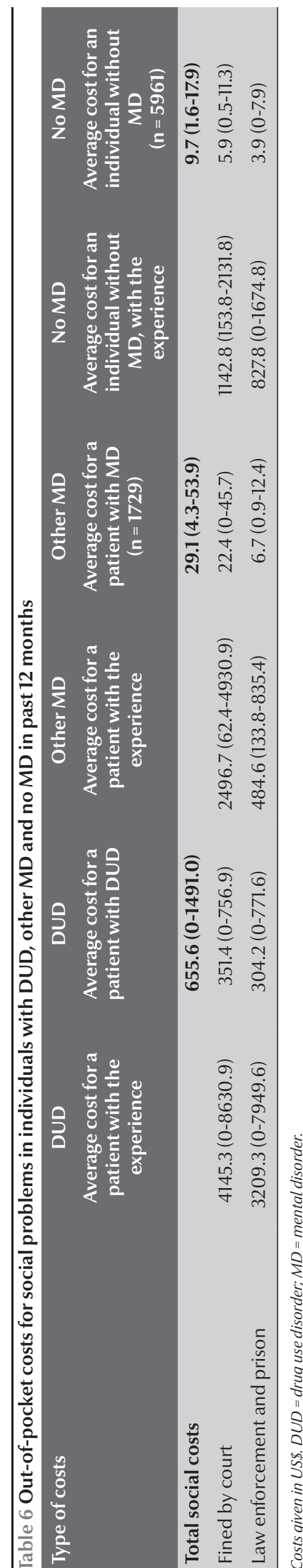

cost. It is usually considered as loss of productivity and measured by the value of the days out of work (32). Using this method, our study showed that an employed person with DUD is out of work for an average of 44 days a year, which is more than twice that of those with other MD. This costs US\$598 for an average employed person. Drug abusers tend to have low participation in the legitimate labour force. On average, employed addicts work infrequently or in lowpaid jobs because of drug intoxication or associated health problems. Others turn away from the legitimate economy to obtain income from the drug trade or other illegal activities. Lastly, others may not work while they are incarcerated for drug-related crimes (31). The estimations we provided by assessing the cost of work absenteeism are lower than the total costs due to loss of productivity. We only assessed the number of days out of work for those who were employed. However, the extent of loss of productivity was greater than this. This measurement did not include losses due to unemployment and disablement. We showed that the probability of being unemployed in those with DUD was 2 times higher than in those with other $\mathrm{MD}$ and 3 times higher than in those with no MD. In addition, reduced job performance while at work was not assessed. Decreased productivity of other family members for compensating the roles of patients when they are disabled, hospitalized or imprisoned are other sources of indirect cost that were not calculated in our measurement.

This study is significant in that it is believed to be the first attempt in the Islamic Republic of Iran and the Middle Eastern Region to investigate out-of-pocket costs of drug abuse from a nationally representative sample. We have quantified the main expenses that the patients or their families pay for the consequences of drug use. The other out-of-pocket costs not included in our study are costs of using traditional services for medical illnesses and driving penalties.

We benefited from using a bottom-up cost-of-illness study method. Gustavsson et al. have described the benefits and disadvantages of this method. Bottom-up studies are often more complete, in terms of the resources, and more accurate in selection of persons, because information on diagnosis is usually scant in the available national statistics. The disadvantage of bottomup studies is the probability of doublecounting costs when a person suffers from several disorders. It is difficult to determine which one is causing the costs. This problem is handled in most cost-of-illness studies by trying to separate and only count the specific costs due to the disorder, rather than the total cost of a patient with the disorder (16). We used this method and asked the person to report separately for the costs of mental/drug use problems and medical illnesses. In some cases like inpatient care, we did not separate costs for drugrelated problems with costs of mental problems, therefore, we reported both costs together. We also used the approach of comparing the cost for patients with DUD with 2 control groups with other or no MD, and considered the difference to be caused by DUD. This approach was first described by Hodgson and Meiners (33) and was used for cost analyses thereafter.

In addition to the findings of this study, which was from the patients' perspective, there is a need to study the aggregate costs of drug use from payers' and societal perspectives. This can be examined by estimating the direct costs of the drugs, as well as costs attributable to drug use in different sectors of health, criminal justice, employment, victim costs and premature mortality. In addition, estimating intangible costs due to the lower quality of life of the person and significant others are important, but are difficult to assess. Analysis of the payers of the costs is also essential. Governments pay for most of the health 
services (such as for HIV infection), criminal justice and welfare services (for lost productivity). Moreover, a large budget is spent on combating drug trafficking, including manufacture, distribution and sales, in the Islamic Republic of Iran. Charities and victims are other sources for such services. The Islamic Republic of Iran has had a drug problem for several decades. It is important to investigate the whole expenditure of the country on illicit drugs and its trends over those decades and monitor its effects on the extent of drug use and the associated consequences. Such an effort has been made for 2004, and the total expenditure of the country for drugs was calculated as US\$ 11.7 billion, which was 2-fold higher than the annual income of the country through taxation. Half of the total expenditure was paid by the 2.5 million drug abusers; most of which was direct payment for buying drugs. Drug users' costs for the consequences comprised only a small proportion (34). However, our estimation of US\$2120 out-of-pocket costs for several drug use consequences for an average person with DUD, or US\$ 5.3 billion for the 2.5 million drug abusers is higher than the previous estimation.

In conclusion, those with DUD have lower socioeconomic status and greater probability of being unemployed or disabled, and less probability of being insured. A considerable amount of family resources are spent on the consequences of drug use. The findings suggest the necessity of greater investment in evidence-based drug prevention and treatment interventions, in order to stop the vicious cycle of loss of resources and poverty in the families of individuals with DUD.

\section{Acknowledgements}

We wish to thank Professors Ronald C. Kessler and Ramin Mojtabai for their invaluable contributions to our study.
We also acknowledge support received from Drs. Minoo Mohraz, Hassan E. Razavi, Ali R. Mesdaghinia, Mohammad B.S. Zafarghandi, Abbas A. Nasehi, Emran Razaghi and Mohammad R. Mohammadi, and contributions from Drs. Samaneh Kariman, Maryam Gholamrezaei, Leila M. Goodarzi, Farideh K. Heshmat and Fahima Farrahi in conducting the study. We also wish to thank provincial executive managers and interviewers, as well as all the participants in the study.

Funding: The IranMHS was financially supported by the Ministry of Health through the contract number 132-1491 of Tehran University of Medical Sciences and the contract number 89-D432-143 of the Mental Health Research Network. The funding source had no role in the study design; the collection, analysis and interpretation of data; writing of the report; and in the decision to submit the article for publication.

Competing interests: None declared.

\section{References}

1. Amin-Esmaeili M, Rahimi-Movaghar A, Sharifi V, Hajebi A, Radgoodarzi R, Mojtabai R, et al. Epidemiology of illicit drug use disorders in Iran: prevalence, correlates, comorbidity and service utilization results from the Iranian Mental Health Survey. Addiction. 2016 Oct;111(10):1836-47. PMID:27177849

2. World drug report 2015. Vienna: United Nations Office on Drugs and Crime; 2015 (https://www.unodc.org/documents/ wdr2015/World_Drug_Report_2015.pdf, accessed 15 March 2017).

3. Rahimi-Movaghar A, Amin-Esmaeili M. Haghdoost AA, Sadeghirad B, Mohraz M. HIV prevalence amongst injecting drug users in Iran: a systematic review of studies conducted during the decade 1998-2007. Int J Drug Policy. 2012 Jul;23(4):271-8. PMID:22000694

4. Malekinejad M, Navadeh S, Lotfizadeh A, Rahimi-Movaghar A, Amin-Esmaeili M, Noroozi A. High hepatitis C virus prevalence among drug users in Iran: systematic review and meta-analysis of epidemiological evidence (2001-2012). Int J Infect Dis. 2015 Nov;40:116-30. PMID:26460088

5. Amin-Esmaeili M, Rahimi-Movaghar A, Haghdoost AA, Mohraz M. Evidence of HIV epidemics among non-injecting drug users in Iran: a systematic review. Addiction. 2012 Nov;107(11):192938. PMID:22551085

6. Naghavi M, Shahraz S, Sepanlou SG, Dicker D, Naghavi P, Pourmalek F, et al. Health transition in Iran toward chronic diseases based on results of Global Burden of Disease 2010. Arch Iran Med. 2014 May;17(5):321-35. PMID:24784861
7. Cartwright WS. Economic costs of drug abuse: financial, cost of illness, and services. J Subst Abuse Treat. 2008 Mar;34(2):22433. PMID:17596904

8. French MT, Martin RF. The costs of drug abuse consequences: a summary of research findings. J Subst Abuse Treat. $1996 \mathrm{Nov}$ Dec;13(6):453-66. PMID:9219142

9. Rehm J, Baliunas D, Brochu S, Fischer B, Gnam W, Patra J, et al. The costs of substance abuse in Canada 2002: highlights. Ottawa: Canadian Centre on Substance Abuse; 2006 (http:// www.ccsa.ca/Resource\%20Library/ccsa-011332-2006.pdf, accessed 15 March 2017).

10. Rahimi-Movaghar A, Amin-Esmaeili M, Sharifi V, Hajebi A, Hefazi M, Rad Goodarzi R, et al. The Iranian Mental Health Survey: design and field procedures. Iran J Psychiatry. 2014 Apr;9(2):96-109. PMID:25632287

11. Arabgol F, Alaghband-rad J, Sharifi V, Hakim Shooshtari M, Shabaani A, Davari Ashtiani R, et al. Reliability of a Persian translation of the Composite International Diagnostic Interview (CIDI), section for substance use disorders: in a multicenter study in Iran. Adv Cogn Sci. 2005;7:38-45.

12. Alaghband Rad J. Study of the reliability, validity, and feasibility of Farsi translation of the Composite International Diagnostic Interview (CIDI). In: Ahmadi Abhari SA, Malakooti K, Nasr Esfahani M, Razzaghi EM, Sadeghi M, Yasamy MTs, editors. Mental health effects of Iraqi invasion of Kuwait in a war - torn population of Iran: an epidemiological and financial study of the consequences of the Kuwaiti oil well fire disaster in the aftermath of Iraqi invasion of Kuwait in 1991, United Nations Compensation Commission (UNCC) Monitoring and Assess- 
ment Project. Tehran - Iran: Islamic Republic of Iran Ministry of Health, Committee for Assessment and follow up for Damages Resulting from the Iraq-Kuwait War; 2003.

13. Sharifi V, Assadi SM, Mohammadi MR, Amini $H$, Kaviani $H$, Semnani Y, et al. A Persian translation of the Structured Clinical Interview for Diagnostic and Statistical Manual of Mental Disorders, Fourth Edition: psychometric properties. Compr Psychiatry. 2009 Jan-Feb;50(1):86-91. PMID:19059520

14. Hajebi A, Motevalian A, Amin-Esmaeili M, Hefazi M, Radgoodarzi R, Rahimi-Movaghar A, et al. Telephone versus faceto-face administration of the Structured Clinical Interview for Diagnostic and Statistical Manual of Mental Disorders, Fourth Edition, for diagnosis of psychotic disorders. Compr Psychiatry. 2012 Jul;53(5):579-83. PMID:21820651

15. Sharifi V, Amin-Esmaeili M, Hajebi A, Motevalian A, Radgoodarzi R, Hefazi $M$, et al. Twelve-month prevalence and correlates of psychiatric disorders in Iran: the Iranian Mental Health Survey, 2011. Arch Iran Med. 2015 Feb;18(2):76-84. PMID:25644794

16. Gustavsson A, Svensson M, Jacobi F, Allgulander C, Alonso J, Beghi E, et al. Cost of disorders of the brain in Europe 2010. Eur Neuropsychopharmacol. 2011 Oct;21(10):718-79. PMID:21924589

17. Central Bank of the Islamic Republic of Iran. Foreign exchange rates (http://www.cbi.ir/exrates/rates_en.aspx, accessed 15 March 2017)

18. Statistical Center of Iran. Household expenditure and income 2011 (https://www.amar.org.ir/Portals/0/Files/ abstract/1389/n_h_sh89.pdf, accessed 15 March 2017) (in Persian).

19. Moghadam MN, Banshi M, Javar MA, Amiresmaili M, Ganjavi S. Iranian household financial protection against catastrophic health care expenditures. Iran J Public Health. 2012;41(9):6270. PMID:23193508

20. McCollister KE, French MT, Pyne JM, Booth B, Rapp R, Carr C. The cost of treating addiction from the client's perspective: results from a multi-modality application of the Client DATCAP. Drug Alcohol Depend. 2009 Oct 1;104(3):241-8. PMID:19574000

21. Olsson TM, Fridell M. Women with comorbid substance dependence and psychiatric disorders in Sweden: a longitudinal study of hospital care utilization and costs. BMC Health Serv Res. 2015 Jun 6;15:224. PMID:26048811

22. Thomas CP, Hodgkin D, Levit K, Mark TL. Growth in spending on substance use disorder treatment services for the pri- vately insured population. Drug Alcohol Depend. 2016 Mar 1;160:143-50. PMID:26781063

23. Humphreys K, Wing S, McCarty D, Chappel J, Gallant L, Haberle B, et al. Self-help organizations for alcohol and drug problems: toward evidence-based practice and policy. J Subst Abuse Treat. 2004 Apr;26(3):151-8. PMID:15063905

24. Jafari S, Rahimi-Movaghar A, Craib KJP, Baharlou S, Mathias R. A follow-up study of drug users in Southern Iran. Addict Res Theory. 2010;18(1):59-70.

25. Humphreys K, Blodgett JC, Wagner TH. Estimating the efficacy of Alcoholics Anonymous without self-selection bias: an instrumental variables re-analysis of randomized clinical trials. Alcohol Clin Exp Res. 2014 Nov;38(11):2688-94. PMID:25421504

26. Rahimi-Movaghar A. Khastoo G, Fekri M, Akhondzadeh S. Treatment of addiction by medicinal herbs sellers in Tehran. Hakim Res J. 2008;11(3):11-9 (in Persian).

27. Rockett IR, Putnam SL, Jia H, Chang CF, Smith GS. Unmet substance abuse treatment need, health services utilization, and cost: a population-based emergency department study. Ann Emerg Med. 2005 Feb;45(2):118-27. PMID:15671966

28. Fenoglio P, Parel V, Kopp P. The social cost of alcohol, tobacco and illicit drugs in France, 1997. Eur Addict Res. 2003 Jan;9(1):18-28. PMID:12566794

29. Mark TL, Woody GE, Juday T, Kleber HD. The economic costs of heroin addiction in the United States. Drug Alcohol Depend. 2001 Jan 1;61(2):195-206. PMID:11137285

30. National Institutes of Health, National Institute on Drug Abuse. The economic costs of alcohol and drug abuse in the United States - 1992 (https://archives.drugabuse.gov/EconomicCosts/Index.html, accessed 15 March 2017).

31. Harwood HJ. Societal costs of heroin addiction. In: NIH Consensus Development Conference on Effective Medical Treatment of Heroin Addiction 1997:53.

32. Chisholm D, Diehr P, Knapp M, Patrick D, Treglia M, Simon G. Depression status, medical comorbidity and resource costs. Evidence from an international study of major depression in primary care (LIDO). Br J Psychiatry. 2003 Aug;183:121-31. PMID:12893665

33. Hodgson TA, Meiners MR. Cost-of-illness methodology: a guide to current practices and procedures. Milbank Mem Fund Q Health Soc. 1982 Summer;60(3):429-62. PMID:6923138

34. Mokhtaryan $\mathrm{H}$, Hashemi A. The economy of illicit drugs: an estimation of costs in Iran. Iranian J Soc Probl. 2011 Winter/ Spring;1(4):151-75 (in Persian). 